\title{
Diagnosis Methods for IGBT Open Switch Fault Applied to 3-Phase AC/DC PWM Converter
}

\author{
Won-Sang Im*, Jang-Sik Kim*, Jang-Mok Kim ${ }^{\dagger}$, Dong-Choon Lee**, and Kyo-Beum Lee** \\ $\dagger^{* *}$ School of Electrical Engineering, Pusan National University, Busan, Korea \\ ** Dept. of Electrical Eng., Yeungnam University, Gyeongsan, Korea \\ *** School of Electrical and Computer Eng., Ajou University, Suwon, Korea
}

\begin{abstract}
Fault diagnosis technique of electrical drives is becoming more and more important, since voltage fed converter system has become industrial standard in many applications. Many studies have been conducted an inverter fault diagnosis for induction motors. However, there are few researches about fault diagnosis of 3-phase ac/dc PWM (Pulse Width Modulation) converter compared to the $\mathrm{dc} / \mathrm{ac}$ inverter. The ac/dc converter is the opposite of dc/ac inverter at current flow. Also, inverter and converter have different current patterns under the same condition of IGBT (Insulated gate bipolar transistor) open switch fault. Therefore, it is difficult to apply intact diagnosis methods of inverter to the converter. This paper proposes modified fault detection methods for IGBT open switch fault in 3-phase ac/dc PWM converter by modifying established fault diagnostic methods for dc/ac inverters.
\end{abstract}

Key Words: Converter, Diagnosis, Fault detection, Normalized DC Current Method, Open switch fault, Park's Vector Method

\section{INTRODUCTION}

In recent years, 3-phase ac/dc PWM converter has become the standard in industrial applications due to its advanced features which include sinusoidal input current with unity power factor and high-quality dc output voltage [1]. The reliability of the power conversion systems have been always important issue. So, fault diagnostic methods of the system are required to improve reliability and guarantee scheduled maintenance. It is estimated that about $38 \%$ of the faults in voltage-source power conversion system are due to failures of power devices such as IGBT. Its failures can be broadly categorized as short circuit faults and open switch faults [2].

Short circuit faults are caused by bond wire rupture, impact ionization, gate circuit degradation and over- current [3]. Short circuit faults cause system shutdown because its source is blocked by protection circuits which include circuit breaker and fuses. Otherwise, the system is critically destroyed with damages incurred switching and peripheral device. Therefore, protection circuits are the most critical components that prevent the destabilization of the whole system after short circuit faults occur.

On the other hand, open switch faults can be caused either by device driver failures, the rupture of the connections induced by over-heating, or the lift of bonding wire resulting

\footnotetext{
Manuscript received Aug. 29, 2011; revised Dec. 12, 2011

Recommended for publication by Associate Editor Honnyong Cha.

$\dagger$ Corresponding Author: jmok@pusan.ac.kr

Tel: +82-51-510-2366, Fax: +82-51-513-0212, Pusan Nat'l University

* School of Electrical Eng., Pusan National University, Korea

** Dept. of Electrical Eng., Yeungnam University, Korean

*** School of Electrical and Computer Eng., Ajou University, Korea
}

from thermic cycling [4]. Open switch faults of the system do not cause system shutdown contrary to short circuit faults, but degrades its performance. Such degradations in return represent the source of secondary faults. If such state of abnormal operation lasts for extended period of time, accumulated fatigue under unstable operation may generate malfunctions in several devices of the system. Accordingly, there is high probability of secondary faults occurrence in the load, grid, and converter system. Therefore, diagnostic techniques of power conversion systems are required for monitoring and detecting of open switch faults.

Some diagnosis methods of open switch fault in dc/ac inverter have been developed during the last decade by Mendes, Abramik, Peuget and others [5]-[10]. Most of these fault diagnostic methods for inverters were reviewed by $\mathrm{Bin} \mathrm{Lu}$ [11], [12]. However, there are only few researches done on fault diagnosis of 3-phase ac/dc PWM converter. The ac/dc converter is the opposite of dc/ac inverter at current flow. Also, they have different current patterns each other under the same condition of IGBT open switch fault. Therefore, it is difficult to apply the same kind of diagnosis methods used for inverter to the converter.

This paper proposes modified fault detection method for IGBT open switch fault in 3-phase ac/dc PWM converter by modifying established fault diagnostic methods for dc/ac inverters. First of all, a comparison of IGBT open switch fault is shown in inverter and converter. Then, established fault diagnosis methods of Mendes and Abramik are applied in ac/dc converter. Subsequently, the modified fault diagnosis methods are proposed. Finally, the experimentations are performed to verify the proposed methods. 


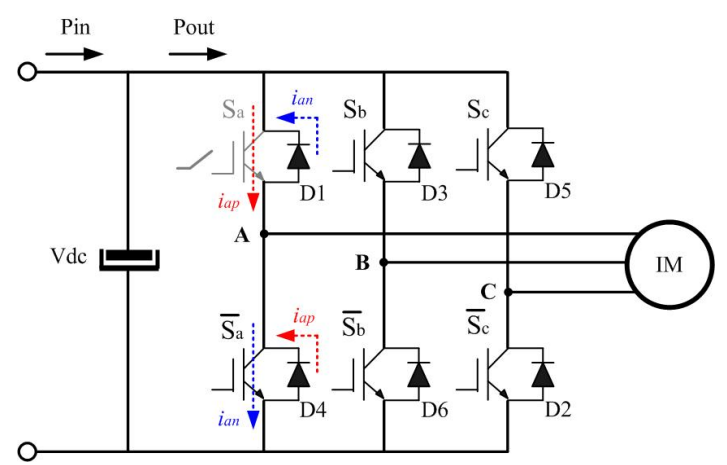

Fig. 1. 3-phase PWM inverter ( $S_{a}$ open).

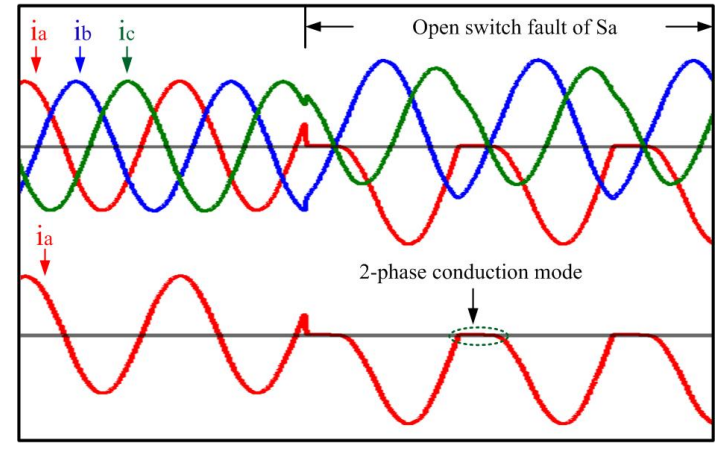

Fig. 2. Phase currents in $S_{a}$ open fault of inverter.

\section{COMPARISON OF IGBT OPEN SWITCH FAULT IN INVERTER AND CONVERTER}

\section{A. IGBT Open Switch Faults in DC/AC Inverter}

In IGBT open faults of dc/ac inverter, a faulty phase current can either be positive or negative depending on the damaged switch. Fig. 1 shows a configuration of 3-phase PWM inverter and induction motor. The $i_{a p}$ and $i_{a n}$ are positive and negative current in a-phase, respectively. If IGBT open switch fault in $S_{a}$ occurs during normal operation as shown in Fig. 1, phase current waveforms of Fig. 2 are appeared. After the fault of $S_{a}$, a-phase has only the negative current because the faulty switch $S_{a}$ cannot conduct any current as shown in Fig. 2. The freewheeling diode $\mathrm{D}_{4}$ in Fig. 1 also cannot conduct any current because A-pole voltage is higher than other two poles. The other phase currents operate 2-phase conduction mode while a-phase current is zero.

\section{B. IGBT Open Switch Faults in AC/DC Converter}

Phenomenon of IGBT open switch fault in ac/dc converter has a big difference compared to the one in ac/dc inverter. Fig. 3 shows a configuration of 3-phase ac/dc PWM converter with a fault in $S_{a}$ indicated by an open gate connection. Fig. 4 shows phase current waveforms before and after IGBT open switch fault of $S_{a}$. Contrary to inverter, a-phase current has both positive and negative value.

As shown in Fig. 3, the positive current of a-phase conducts through $\overline{S_{a}}$ and $D_{1}$, and the negative current of a-phase conducts through $S_{a}$ and $D_{4}$. Therefore, the open fault of switch $\mathrm{S}_{\mathrm{a}}$ does not affect the positive current of the ac/dc converter as shown in Fig. 4. However, the fault causes the block of the negative current through $S_{\mathrm{a}}$. So, 2-phase conduction mode of Fig. 4 is represented. Then, unlike the inverter, negative

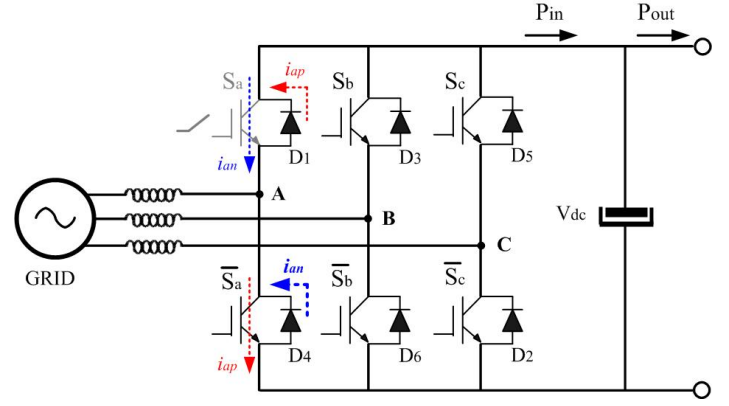

Fig. 3. 3-phase ac/dc PWM converter ( $S_{a}$ open).

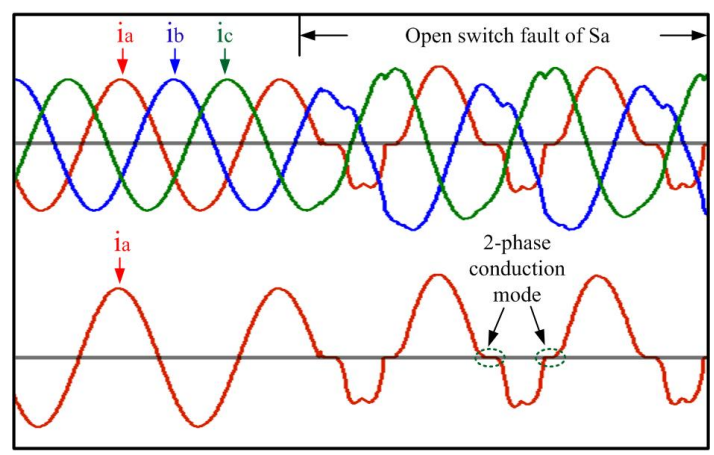

Fig. 4. Phase currents in $S_{a}$ open fault in ac/dc converter.

current is generated during specific interval as shown in Fig. 4. It is because freewheeling diode $\mathrm{D}_{4}$ is conducted when Apole voltage is lower than the other poles.

As shown in Fig. 4, the shape of the distorted a-phase negative current resembles the current of 3-phase rectifier. However, the shape is not always the same. As shown in Fig. 5 , the shapes are various according to the control performance, reactor capacity, load power and reference DC-link voltage.

In general, the high performance converter is operated by symmetrical SVPWM (Space Vector PWM) and digital PI (Proportional Integral) controller. All gains of PI controller relate to the control performance so that current shapes are a little different. It follows that reactor capacity not only relates to the proportional gain of PI current controller but also determines the slope of the current. As a result, the resulting waveforms in faulty condition differ from each other according to the reactor capacity as shown in Fig. 5. If load power is high, the input currents are large. Hence, the circulating current through freewheeling diode $\mathrm{D}_{4}$ is also increased in $\mathrm{S}_{\mathrm{a}}$ fault condition. As shown in Fig. 5, the higher load power, the larger the negative current will become. Fig. 6 illustrates different outcomes resulting from the change of DClink voltage reference. In $S_{a}$ open switch fault, the zero vector of $(1,1,1)$ cannot be available due to the faulty switch. Instead of the zero vector, it acts as active vector $(0,1,1)$. Therefore, the current is distorted by zero vector size of $(1,1,1)$. The higher the reference DC-link voltage, the longer the zero vector time becomes in SVPWM. Accordingly, if the DC-link voltage reference gets high enough, the current tends to deteriorate under the open switch fault condition.

In addition, Fig. 6 also shows PWM switching patterns before and after open switch fault. The switching patterns are distorted due to the abnormal vectors related switch $S_{a}$. 


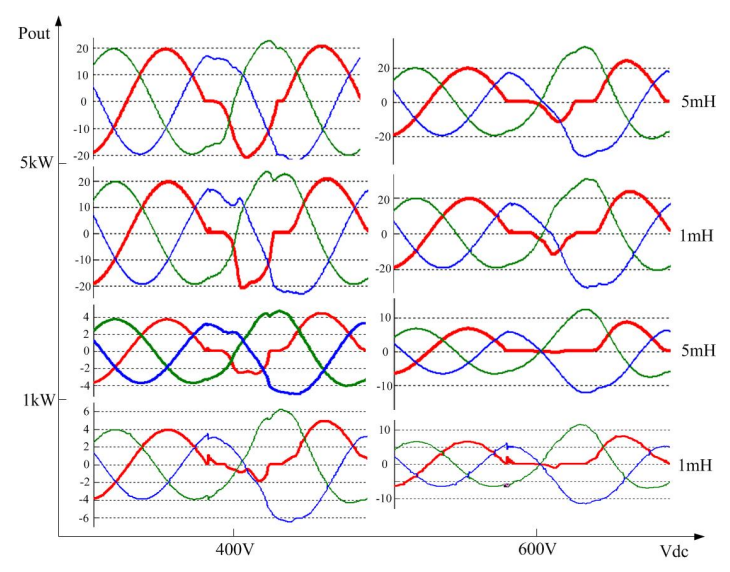

Fig. 5. Shapes of distorted current $\left(\mathrm{S}_{\mathrm{a}}\right.$ open).

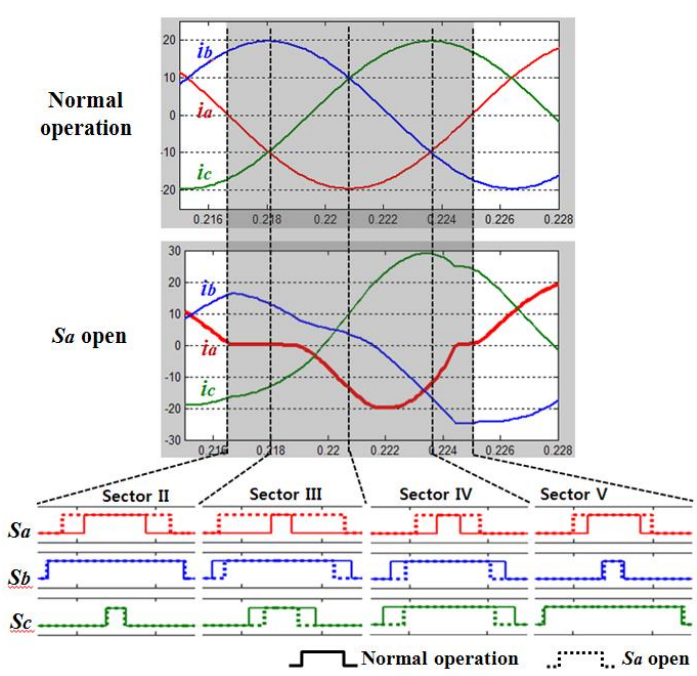

(a) $600 \mathrm{~V}($ Pout $=5 \mathrm{~kW})$.

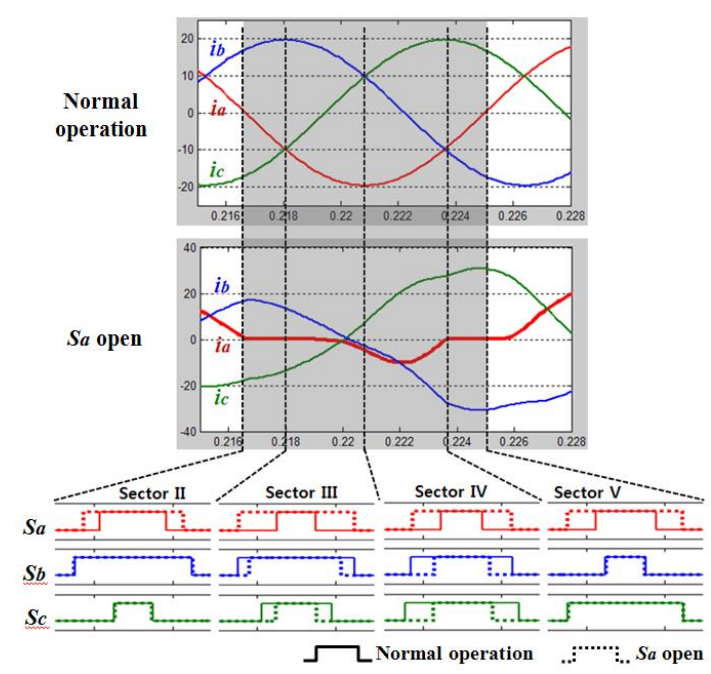

(b) $400 \mathrm{~V}($ Pout $=5 \mathrm{~kW})$.

Fig. 6. Effect of the change in DC-link voltage reference.

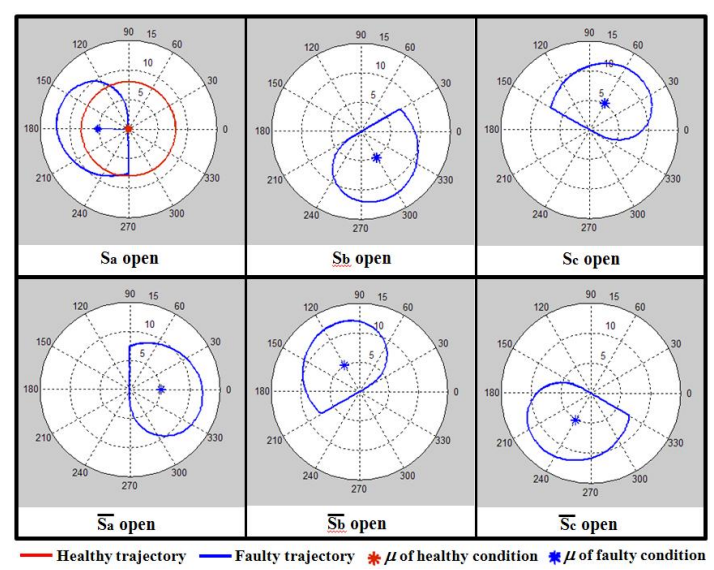

Fig. 7. $\mu$ and $d q$-current trajectories under open switch fault condition of inverter.

\section{An Application of Existing Inverter Methods FOR AC/DC PWM CONVERTER}

It is difficult to apply the same kind of diagnosis methods used for inverter to the converter because of aforementioned differences between ac/dc converter and dc/ac inverter. Therefore, this paper suggests application methods through modifications of exiting Park's Vector Method and Normalized DC Current Method.

\section{A. An application of Park's Vector Method}

Park's Vector Method [7] takes advantage of an average value of $d$ - and $q$-axis currents during one cycle. 3-phase phase currents can be transformed to the 2-phase $d q$-currents by Park's Vector transformation of (1). Then, the averages during one cycle in $d q$-currents are calculated by (2). The obtained two average values can be expressed as one point $\mu$ on $d q$-coordinate by (3).

$$
\begin{gathered}
i_{d}^{s}=\frac{2}{3} i_{a}^{s}-\frac{1}{3}\left(i_{d}^{s}+i_{c}^{s}\right), i_{q}^{s}=\frac{1}{\sqrt{3}}\left(i_{b}^{s}-i_{c}^{s}\right) \\
\mu_{x}=\frac{1}{N} \sum_{k=1}^{N} i_{x}(k \tau) \\
\mu=\mu_{d}+j \mu_{q}=M_{\mu} \angle \theta_{\mu} \\
M_{\mu}=\sqrt{\left(\mu_{d}\right)^{2}+\left(\mu_{q}\right)^{2}}, \theta_{\mu}=\tan ^{-1} \frac{\mu_{q}}{\mu_{d}} .
\end{gathered}
$$

Fig. 7 shows $d q$-current trajectories and point $\mu$ under each open switch fault condition. First cell of Fig. 7 is result of Fig. 2. In normal operation, the trajectory and average point are a circle and an origin, respectively. But, they are a half circle and a biased point in left half-plain under the $S_{a}$ open fault condition. Faults of the other switches appear shapes rotated by 60 degrees as shown in Fig. 7. So, the biased point $\mu$ can be a standard for open fault detection. Therefore, Park's Vector Method can find the switch of the open fault from the argument of the point when the magnitude of $\mu$ exceeds a certain threshold value as shown in Table I.

If Park's Vector method applies to ac/dc converter, the results are shown in Fig. 8. First cell of Fig. 8 is result of Fig. 4. The half circle is reversed by 180 degrees compared to Fig. 7. However, it does not need to be considered due to 


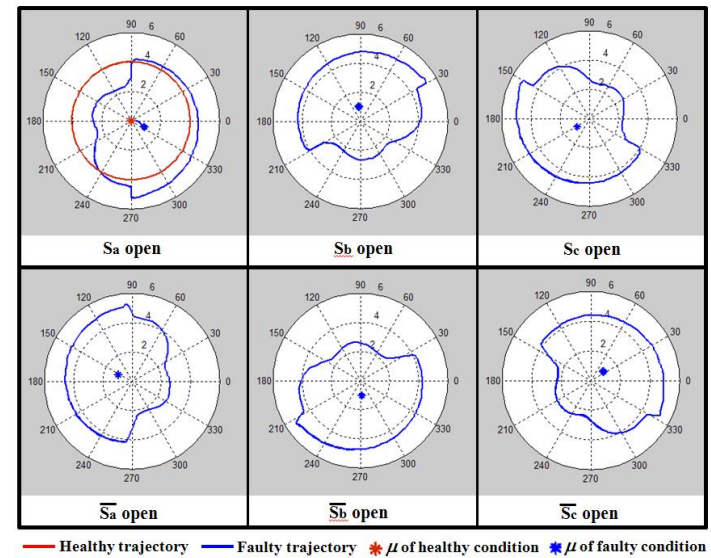

Fig. 8. $\mu$ and $d q$-current trajectories under open fault condition of ac/dc converter.

TABLE I

Localization of Fault with Park's Vector Method in DC/AC INVERTER

\begin{tabular}{|c|c|c|}
\hline $\begin{array}{l}\text { Open } \\
\text { Switch }\end{array}$ & Magnitude $\mu$ & Interval of $\theta_{\mu}$ \\
\hline $\mathbf{S a}$ & \multirow{6}{*}{$\begin{array}{l}\text { Exceed } \\
\text { Threshold }\end{array}$} & $150<\theta_{\mu}<210$ \\
\hline$\overline{\mathbf{S a}}$ & & $330<\theta_{\mu}<30$ \\
\hline $\mathrm{Sb}$ & & $270<\theta_{\mu}<330$ \\
\hline$\overline{\mathrm{Sb}}$ & & $90<\theta_{\mu}<150$ \\
\hline $\mathbf{S c}$ & & $30<\theta_{\mu}<90$ \\
\hline$\overline{\mathbf{S c}_{\mathrm{c}}}$ & & $210<\theta_{\mu}<270$ \\
\hline
\end{tabular}

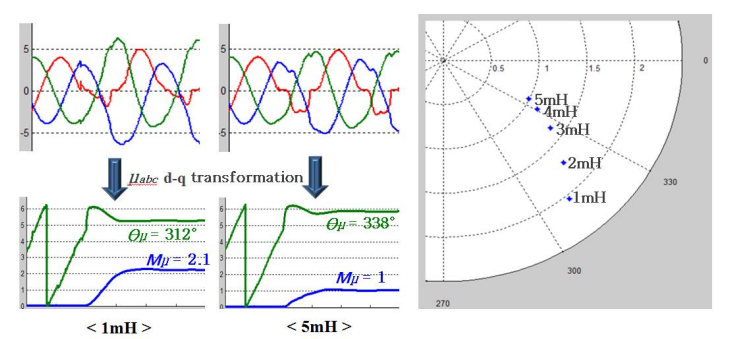

Fig. 9. The detected point of $\mu$ according to installed reactor in case of $\mathrm{S}_{\mathrm{a}}$ open fault.

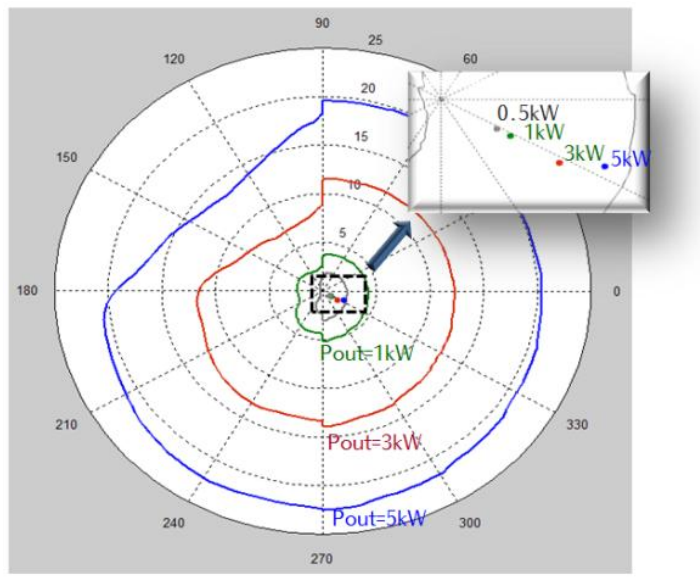

Fig. 10. The detected point of $\mu$ according to load power in open fault of $S_{a}$.
TABLE II

Proposed Localization of Fault with Park's Vector Method in AC/DC CONVERTER

\begin{tabular}{|c|c|c|}
\hline $\begin{array}{l}\text { Open } \\
\text { Switch }\end{array}$ & Magnitude $\mu$ & Interval of $\theta_{\mu}$ \\
\hline $\mathbf{S a}$ & \multirow{6}{*}{$\begin{array}{l}\text { Exceed } \\
\text { Threshold }\end{array}$} & $300<\theta_{\mu}<0$ \\
\hline$\overline{\mathbf{S a}}$ & & $120<\theta_{\mu}<180$ \\
\hline $\mathrm{Sb}_{\mathbf{b}}$ & & $60<\theta_{\mu}<120$ \\
\hline$\overline{\mathbf{S}_{\mathbf{b}}}$ & & $240<\theta_{\mu}<300$ \\
\hline $\mathbf{S c}$ & & $180<\theta_{\mu}<240$ \\
\hline$\overline{\mathbf{S c}_{\mathbf{c}}}$ & & $0<\theta_{\mu}<60$ \\
\hline
\end{tabular}

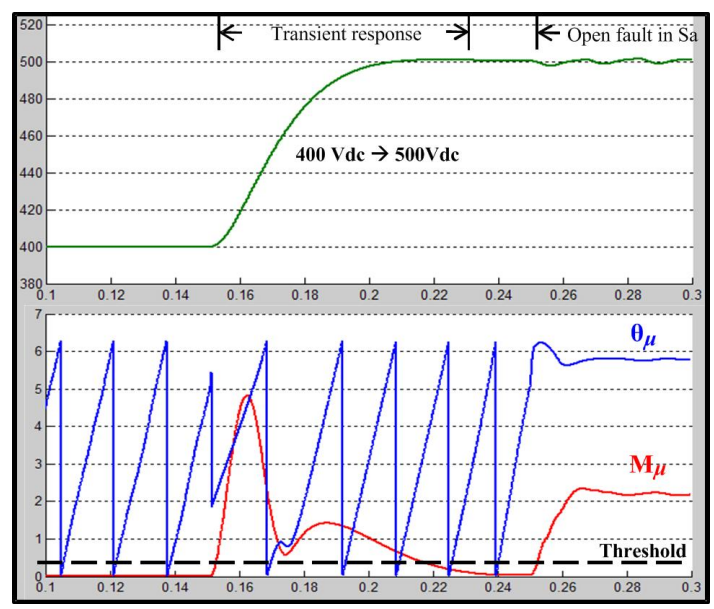

Fig. 11. Transient state and fault detection in modified Park's Vector Method.

the difference in direction of current sensor. But converter has both positive and negative current so that $\mu$ is smaller than it of inverter. Also, the argument is rotated by small amount because the trajectory is biased to one side. In addition, Fig. 9 shows various $\mu$ points according to the reactor capacity. As mentioned earlier, reactor capacity affects the control performance and the slope of current so that magnitude and argument of $\mu$ are varied at the same time similarly to Fig. 9. Fig. 10 shows the trajectories and $\mu$ points according to the load power. The higher power load, the larger magnitude $\mu$ becomes. As a result, the threshold of converter for the fault detection should be smaller than the threshold of inverter. Also, the localized $\theta_{\mu}$ should be rotated by 30 degrees as shown in Table II.

As shown in Fig. 11, magnitude of $\mu$ can exceed the threshold value at the transient state - i.e. the change of the load or reference voltage. Also, transient time of $\mu$ in open switch fault is smaller than transient time of voltage change. Therefore, the level of certainty of open switch fault can be decided after threshold value exceeds maximum transient time. The algorithm that considers transient state can be represented in the flowchart of Fig. 12.

\section{B. An application of Normalized StateDC Current Method}

Normalized DC Current Method [8] developed by Abramik also uses the direct component $\mu$ of the phase currents through 


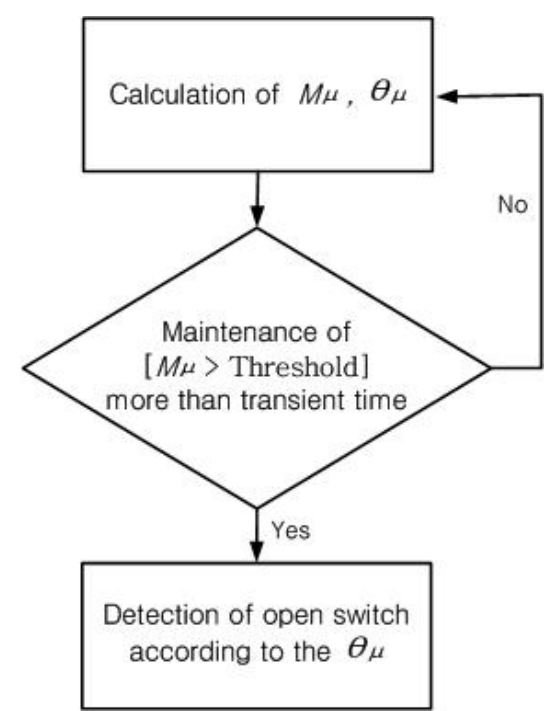

Fig. 12. Flowchart of modified Park's Vector Method.

TABLE III

DETECTION METHOD IN DC/AC INVERTER

\begin{tabular}{|c|c|c|c|c|c|c|}
\hline Open Switch & $d_{1 \_a}$ & $d_{1 \_b}$ & $d_{1 \_} c$ & $d_{2 \_a}$ & $d_{2 \_b}$ & $d_{2 \_} c$ \\
\hline Sa & 0 & 1 & 1 & 1 & 0 & 0 \\
\hline$\overline{\mathrm{Sa}}$ & 1 & 0 & 1 & 0 & 1 & 0 \\
\hline $\mathrm{Sb}$ & 1 & 1 & 0 & 0 & 0 & 1 \\
\hline$\overline{\mathrm{Sb}}$ & 1 & 0 & 0 & 1 & 0 & 0 \\
\hline Sc & 0 & 1 & 0 & 0 & 1 & 0 \\
\hline$\overline{\mathrm{Sc}_{\mathrm{c}}}$ & 0 & 0 & 1 & 0 & 0 & 1 \\
\hline
\end{tabular}

(3). The first order DFT coefficients of the phase currents are calculated by (4) and (5) to obtain independent values from the load. As shown in (6), dividing the direct component $\mu$ by the calculated DFT coefficient provides the diagnostic variable $\gamma$.

$$
\begin{gathered}
a_{1 \_x}=\frac{2}{N} \sum_{k=1}^{N} i_{x}(k \tau) \cos \left(\frac{2 \pi k}{N}\right) \\
b_{1 \_x}=\frac{2}{N} \sum_{k=1}^{N} i_{x}(k \tau) \sin \left(\frac{2 \pi k}{N}\right) \\
\gamma_{x}=\frac{\mu_{x}}{\sqrt{\left(a_{1 \_}\right)^{2}+\left(b_{1 \_}\right)^{2}}} .
\end{gathered}
$$

For open switch fault detection in dc/ac inverter, the $\gamma$ is compared to thresholds as shown in (7) and (8). Then, the faulty switch can be identified from table III. The threshold of 0.45 is a value obtained by an estimation based on experience, as stated in [8].

$$
\begin{gathered}
d_{1 \_x}=\left\{\begin{array}{c}
1: \gamma_{x}>0 \\
0: \gamma_{x} \leq 0
\end{array}\right. \\
d_{2 \_x}=\left\{\begin{array}{c}
1:\left|\gamma_{x}\right|>0.45 \\
0:\left|\gamma_{x}\right| \leq 0.45
\end{array} .\right.
\end{gathered}
$$

Fig. 13 shows diagnostic variable $\gamma$ according to switch and load power in open switch faults of converter. If conditions

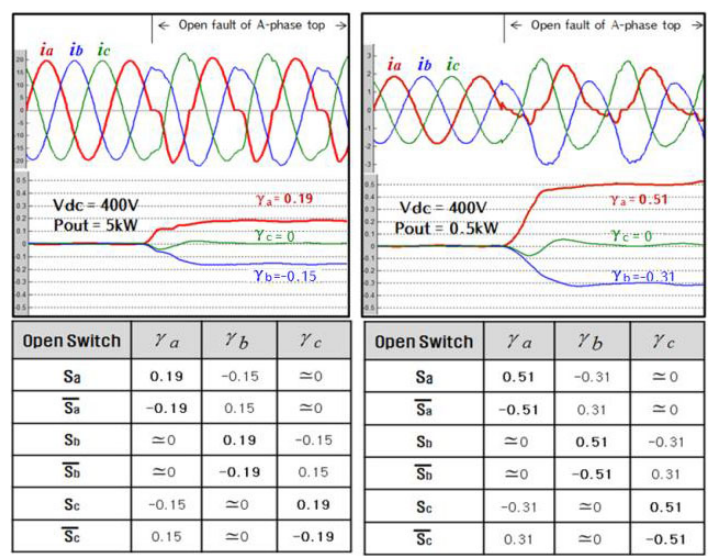

Fig. 13. $\gamma_{a}, \gamma_{b}, \gamma_{c}$ according to load power and switch in open switch faults of converter.

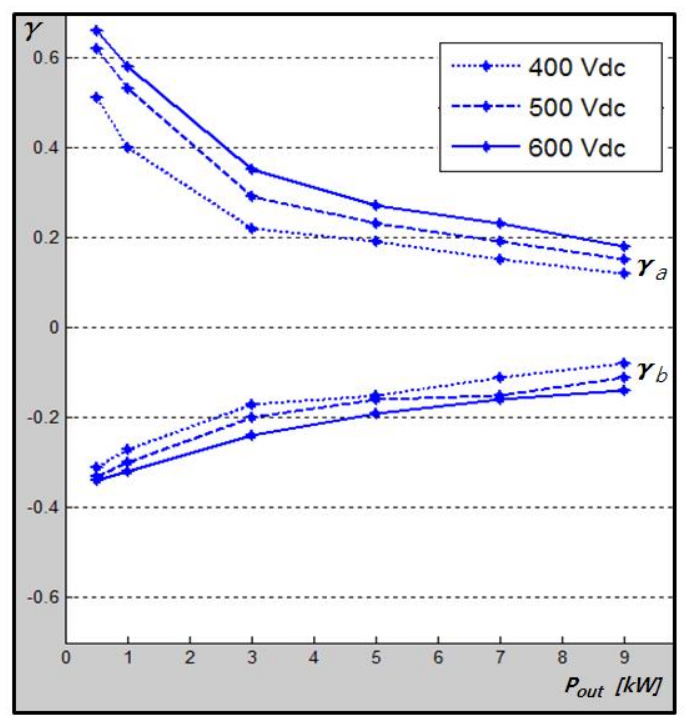

Fig. 14. $g_{a}$ and $g_{b}$ according to load power and DC-link voltage in open fault of $\mathrm{S}_{\mathrm{a}}$.

of (7) and (8) are applied in results of Fig. 13, open fault detection is possible in right side waveform but impossible in left side waveform. In the case of left side waveform, $\gamma$ is lower than 0.45 even if open switch fault occurs. This is due to the presence of current through freewheeling diode as mentioned earlier.

Fig. 14 shows $\gamma_{a}$ and $\gamma_{b}$ according to load power and DClink voltage in open fault of $S_{a}$. As shown in Fig. 14, if the same kind of diagnosis method for inverters is applied to converters, it is impossible to detect the open switch fault in various conditions let alone few exceptional cases. Therefore, modified fault detection method is proposed in Table IV. The faulty switch can be found by comparison of $\gamma_{a}, \gamma_{b}$ and $\gamma_{c}$. The threshold of 0.05 is suitable for open fault detection of $\mathrm{ac} / \mathrm{dc}$ converter given large amount of experimentations and analyses are conducted to support the data.

In this method, the transient performance is excellent due to the use of load independent variable $\gamma$. Thus, the fault detection time can be shorter than from previous method. As shown in Fig. 15, the distortion time of $\gamma$ is shorter than half cycle in transient state by change of DC-link voltage. Therefore, the algorithm considering transient state can be represented in the 
TABLE IV

Proposed Fault Detection Method for AC/DC Converter

\begin{tabular}{|c|c|c|}
\hline Open Switch & \multicolumn{2}{|c|}{ Comparison of $\gamma_{\text {abc }}$} \\
\hline Sa & $\gamma_{a}>$ threshold & \multirow{2}{*}{$\left|\gamma_{a}\right|>\left|\gamma_{b}\right|$ and $\left|\gamma_{a}\right|>\left|\gamma_{c}\right|$} \\
\hline$\overline{\mathrm{Sa}}$ & $\gamma_{a}<-$ threshold & \\
\hline $\mathrm{Sb}$ & $\gamma_{b}>$ threshold & \multirow{2}{*}{$\left|\gamma_{b}\right|>\left|\gamma_{c}\right|$ and $\left|\gamma_{b}\right|>\left|\gamma_{a}\right|$} \\
\hline$\overline{\mathrm{Sb}}$ & $\gamma_{b}<-$ threshold & \\
\cline { 1 - 2 } $\mathrm{Sc}$ & $\gamma_{c}>$ threshold & \multirow{2}{*}{$\left|\gamma_{c}\right|>\left|\gamma_{a}\right|$ and $\left|\gamma_{c}\right|>\left|\gamma_{b}\right|$} \\
\hline$\overline{\mathrm{Sc}}$ & $\gamma_{c}<-$ threshold & \\
\hline
\end{tabular}

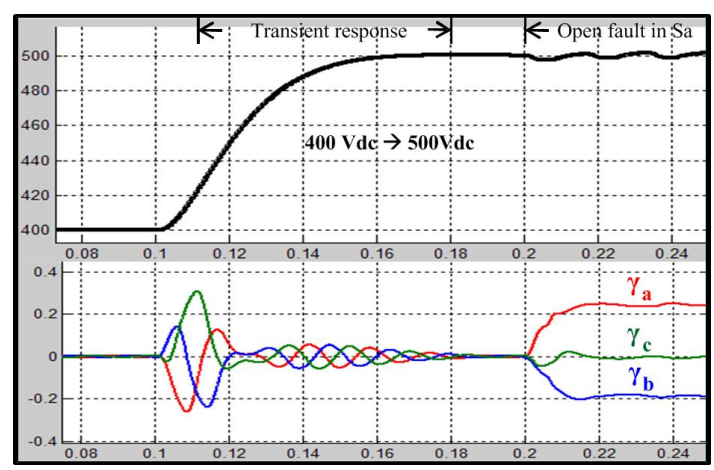

Fig. 15. Transient state and fault detection in modified Normalized DC Current Method.

flowchart of Fig. 16.

\section{Measurement Results}

The experimental setup and overall block diagram are shown in Fig. 17 and Fig. 18, respectivley. 10[kW] 3-phase back to back converter with $5[\mathrm{mH}]$ reactor and $10[\mathrm{~kW}]$ load bank are used as shown in Fig. 17. The converter is controlled by PI control, which uses SVPWM to regulate the DC-link voltage as shown in Fig. 18. There is a generation circuit for open switch fault. Two methods are briefly summarized in the bottom two block diagrams of Fig. 18, respectively.

\section{A. Experimental Results of Modified Park's Vector Method for AC/DC Converter}

Fig. 19 shows experimental results of $\mu$ and $d q$-current trajectories in open switch fault. The test is performed in the $400[\mathrm{~V}] \mathrm{DC}$-link and $1[\mathrm{~kW}]$ load. Magnitude of $\mu$ is about 1 and arguments of $\mu$ are different from one another according to the open fault switch. It follows that Fig. 19 shows similar outcome as simulation results of Fig. 8 .

Fig. 20 shows faulty phase current and trajectory of $\mu$ in six faulty cases using modified Park's Vector Method. $\mu$ moves from the origin to outer region when open switch faults occur. The threshold value of 0.5 is used in this experiment. If $\mu$ is bigger than the threshold value, the faulty switch is detected by the argument of $\mu$ from Table II once latent time of $60[\mathrm{~ms}]$ has elapsed. In this modified Park's Vector Method, latent time of $60[\mathrm{~ms}]$ is needed due to the false detection of transient state as illustrated in Fig. 21 like a simulation result of Fig. 11.

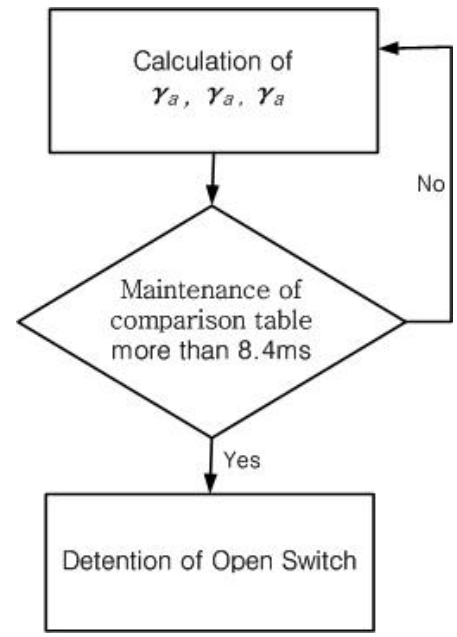

Fig. 16. Flowchart of modified Normalized DC Current Method.

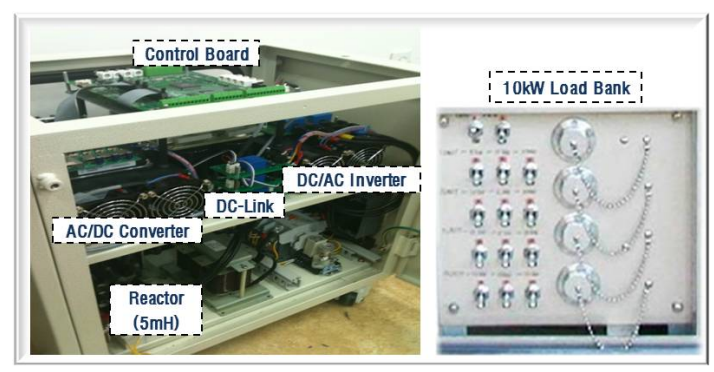

Fig. 17. Experimental setup.
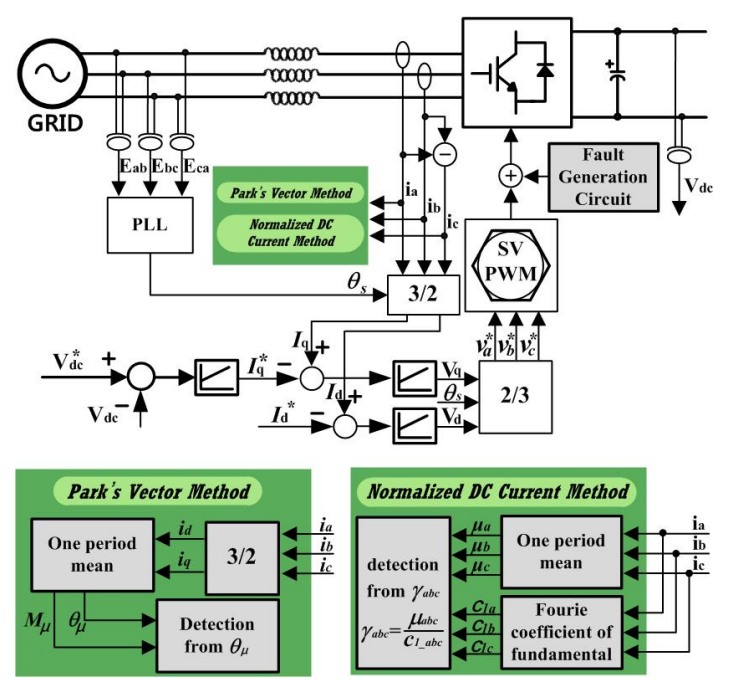

Fig. 18. Overall block diagram.

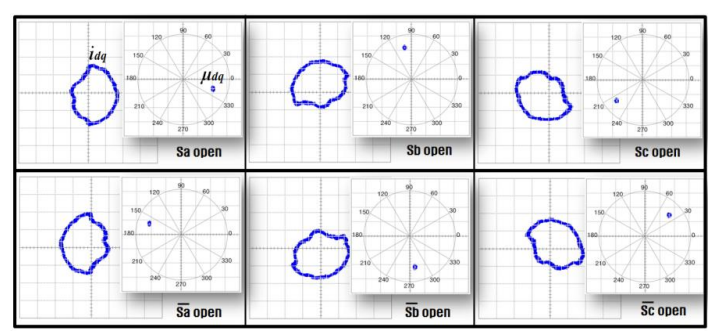

Fig. 19. Experimental results of $\mu$ and $d q$-current trajectories under open fault condition of ac/dc converter. 


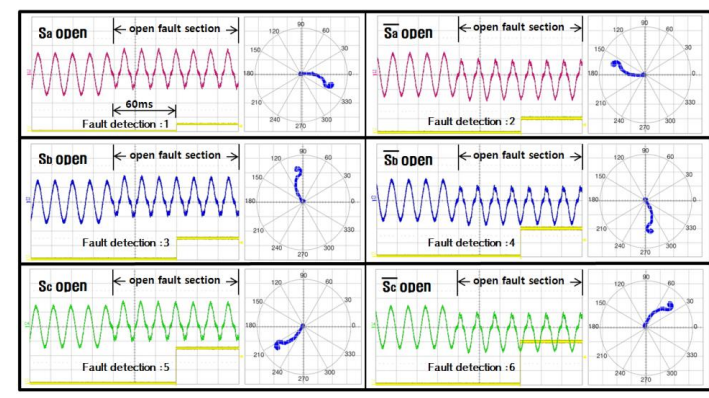

Fig. 20. Diagnosis of open switch fault using modified Park's Vector Method for ac/dc converter.

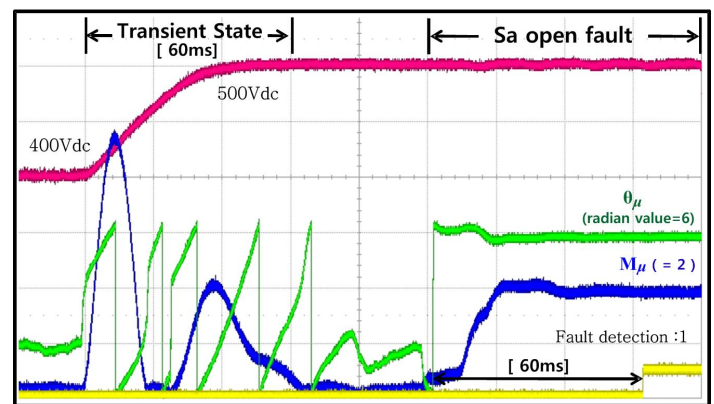

Fig. 21. Transient state and fault detection in modified Park's Vector Method.

Fig. 20 shows faulty phase current and trajectory of $\mu$ in six faulty cases using modified Park's Vector Method. $\mu$ moves from the origin to outer region when open switch faults occur. The threshold value of 0.5 is used in this experiment. If $\mu$ is bigger than the threshold value, the faulty switch is detected by the argument of $\mu$ from Table II once latent time of $60[\mathrm{~ms}]$ has elapsed. In this modified Park's Vector Method, latent time of $60[\mathrm{~ms}]$ is needed due to the false detection of transient state as illustrated in Fig. 21 like a simulation result of Fig. 11.

\section{B. Experimental Results of Modified Normalized StateDC Current Method for AC/DC Converter}

Fig. 22 shows experimental results of fault detection using modified Normalized DC Current Method. The test is performed under the conditions with DC-link voltage of 400[V] and load power of $2.5[\mathrm{~kW}$. Thus, $\gamma$ values of faulty phase are nearly 0.28 or -0.28 from Fig. 14 as shown in Fig. 22. Threshold of 0.05 and latent time of $8.4[\mathrm{~ms}]$ are used from aforementioned explanations. All detection results of six cases are shown in each fault detection signal. Fig. 23 shows transient state and fault detection like a simulation result of Fig. 15. During 60[ms] of transient state, the distortion of $\gamma$ is small due to the load independent property of the method. Therefore, latent time of $8.4[\mathrm{~ms}]$ which defines half cycle of fundamental frequency is enough for the open fault detection. Under the conditions with DC-link voltage of 500[V] and load power of $3[\mathrm{~kW}]$, the $\gamma$ value of faulty a-phase is about 0.3 as shown in Fig. 23. It can be confirmed through Fig. 14.

\section{C. comparison of the modified methods}

Park's Vector Method has the drawback of slower detection time than Normalized DC Current Method, because the latent time is longer. The detection time of Park's Vector Method

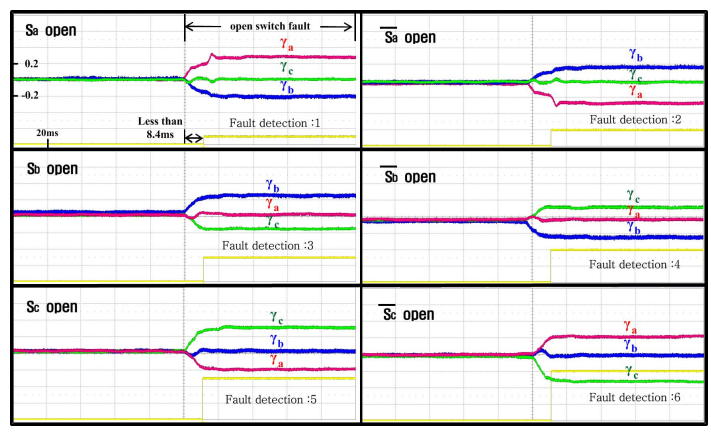

Fig. 22. Diagnosis of each open switch fault using modified Normalized StateDC current method for converter.

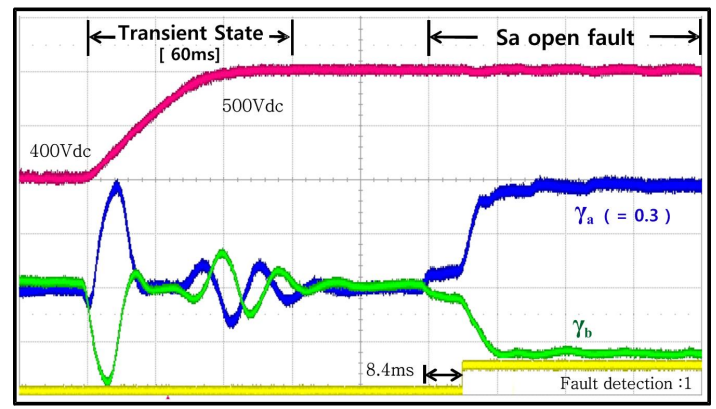

Fig. 23. Transient state and fault detection in modified Normalized DC Current Method.

depends on load characteristic of transient state. If the latent time is too short, it can generate the false detection signal. However, in Normalized DC Current Method, the latent time is only half cycle of fundamental frequency because the $\gamma$ vibrates with fundamental frequency in transient state.

Park's Vector Method has a drawback in low load power. If the load is low, magnitude of $\mu$ is too small. Thus, the threshold should be lower for the fault detection. As a result, the probability of false detections increases due to low threshold. On the other hand, Normalized DC Current Method is good in low load because $\gamma$ is normalized by currents. However, Normalized DC Current Method has a drawback in high load power. As shown in Fig. 14, the higher load power, the lower $\gamma$ becomes. Also two absolute $\gamma$ becomes closer to each other with high load. Hence, the fault detection becomes ambiguous. Table V shows comparison of two modified methods.

\section{CONCLUSIOnS}

This paper analyzed differences of open switch fault between dc/ac inverter and ac/dc converter and proposed alternative fault detection methods for IGBT open switch fault

TABLE V

Comparison of Two Modified Diagnosis Methods in AC/DC CONVERTER

\begin{tabular}{|c|c|c|c|}
\hline \multicolumn{2}{|c|}{ Methods } & $\begin{array}{c}\text { Park's Vector Method } \\
\text { for Converter }\end{array}$ & $\begin{array}{c}\text { Normalized DC Current method } \\
\text { for Converter }\end{array}$ \\
\hline \multirow{2}{*}{ Detection Time } & $>60 \mathrm{~ms}$ & $>8.4 \mathrm{~ms}$ (half cycle) \\
\hline \multirow{3}{*}{ Load } & High & GOOD & ambiguous \\
\cline { 2 - 4 } & Medium & GOOD & GOOD \\
\cline { 2 - 4 } & Low & ambiguous & GOOD \\
\hline
\end{tabular}


in 3-phase ac/dc PWM converter by modifying established two fault diagnostic methods for dc/ac inverters. The analyzed results verified the validity of modified algorithms through the various experiments and simulations.

\section{ACKNOWLEDGMENT}

This work has been supported by KESRI (Korea Electrical Engineering and Science Research Institute) (2009T100100651), which is funded by MKE (Ministry of Knowledge Economy).

\section{REFERENCES}

[1] Y. Suh and T. A. Lipo, "Control scheme in hybrid synchronous stationary frame for $\mathrm{pwm}$ ac/dc converter under generalized unbalanced operating conditions," IEEE Trans. Ind. Appl., Vol. 42, No. 3, pp. 825-835, May/Jun. 2006.

[2] F. W. Fuchs, "Some diagnosis methods for voltage source inverters in variable speed drives with induction machines-A survey," in Proc. IEEE Ind. Conf., pp.1378-1385, 2003.

[3] M. A. Rodriguez, A. Claudio, D. Theilliol, and L. G. Vela, "A new fault detection technique for IGBT based on gate voltage monitoring," in Proc. IEEE Power Electron. Spec. Conf., pp. 1001-1005, 2007.

[4] F. Huang, F. Flett, "IGBT fault protection based on di/dt feedback control," in Proc. IEEE Power Electron. Spec. Conf., pp. 1478-1484, 2007.

[5] A. M. S. Mendes and A. J. M. Cardoso, "Fault diagnosis in a rectifierinverter system used in variable speed ac drives, by the average current park's vector approach," EPE'99. $8^{\text {th }}$ European Conf. on Power Electronics and Applications. pp.1 $9,1999$.

[6] S. Abramik, W. Sleszynski, J. Nieznanski, and H. Piquet, ??A Diagnostic Method for On-line Fault Detection and Localization in addressStreetVSI-Fed AC Drive," EPE $10^{\text {th }}$ European Conf. on Power Electronics and Applications, pp.1 $\sim$, Proceedings of the 2003.

[7] R. Peuget and S. Courtine, ??Fault detection and isolation on a pwm inverter by knowledge-based model," IEEE Trans. on Ind. Appl., Vol.34, No.6, pp.1318-1325, Nov./Dec.1998.

[8] C. Kral and K. Kafka. "Power electronics monnitoring for a controlled voltage source inverter drive with induction machines," Proc. IEEE Power Electronics Specialists Conf., Vol.1, pp.213-217, 2000.

[9] K. Rothenhagen and F.W.Fuchs, "Performance of diagnosis methods for IGBT open circuit faults in three phase voltage source inverters for ac variable speed drives," in Proc. Eur. Power Electron Appl. Conf., pp.1$10,2005$.

[10] D.-E. Kim and D.-C. Lee, "Fault diagnosis of three-phase PWM inverters using wavelet and SVM," Journal of Power Electronics, Vol. 9, No. 3, pp. 377-385, May 2009.

[11] B. Lu and S. K. Sharma, "A literature review of IGBT fault diagnostic and protection methods for power inverters," IEEE Trans. Ind. Appl, Vol. 45, No. 5, pp.1770-1777, Sep./Oct. 2009.

[12] B. Lu and S. K. Sharma, "A survey of IGBT fault diagnostic methods for three-phase power inverters," 2008 International Conference on Condition Monitoring and Diagnosis, pp.1-8, Oct. 2008.

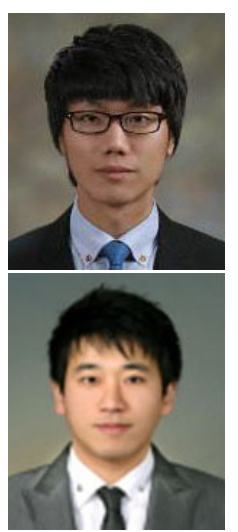

Won-Sang Im was born in Busan, Korea, in 1981. He received his B.S. and M.S. in Electrical Engineering from Pusan National University, Busan, Korea, in 2007 and 2009, respectively. He is currently working toward his Ph.D. at Pusan National University. His research interests include power conversion and electric machine drives.

Jang-Sik Kim was born in Mokpo, Korea, in 1983. He received his B.S. Electrical Engineering from Korea Maritime University in 2010. Now, he is currently working toward his M.S. His current research interests are in the areas of analysis, modeling, design, and control of power converter.

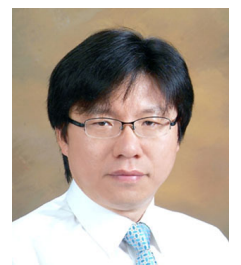

Jang-Mok Kim was born in Busan, Korea, in August 1961. He received his B.S. from Pusan National University in 1988, and his M.S. and Ph.D. from Seoul National University, Korea, in 1991 and 1996, respectively, in the department of Electrical Engineering. From 1997 to 2000, he was a Senior Research Engineer with the Korea Electrical Power Research Institute (KEPRI). Since 2001, he has been with the School of Electrical Engineering, Pusan National University (PNU), where he is currently a Faculty Member. In addition, he is a Research Member of the Research Institute of Computer Information and Communication at PNU. His present interests include the control of electric machines, electric vehicle propulsion, and power quality.

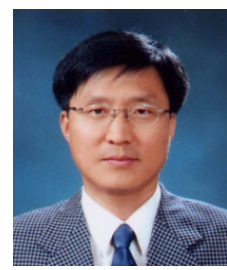

Dong-Choon Lee received his B.S., M.S., and Ph.D. in Electrical Engineering from Seoul National University, Seoul, Korea, in 1985, 1987, and 1993, respectively. He was a Research Engineer with Daewoo Heavy Industry from 1987 to 1988 . Since 1994, he has been a faculty member in the Department of Electrical Engineering, Yeungnam University, Gyeongbuk, Korea. He is serving as a Publication Editor, Journal of Power Electronics, the Korean Institute of Power Electronics, Korea. As a Visiting Scholar, he joined the Power Quality Laboratory, Texas A\&M University, College Station in 1998, the Electrical Drive Center, University of Nottingham, U.K. in 2001, and the Wisconsin Electric Machines \& Power Electronic Consortium, University of Wisconsin, Madison in 2004. Currently, $\mathrm{He}$ is joining the FREEDM System Center, North Carolina State University, in U.S.A. His research interests include ac machine drives, control of power converters, wind power generation, and power quality.

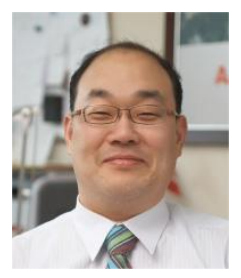

Kyo-Beum Lee (S'02-M'04-SM'11) was born in Seoul, Korea, in 1972. He received the B.S. and M.S. degrees in electrical and electronic engineering from the Ajou University, Korea, in 1997 and 1999, respectively. He received the $\mathrm{Ph} . \mathrm{D}$. degree in electrical engineering from the Korea University, Korea in 2003. From 2003 to 2006, he was with the Institute of Energy Technology, Aalborg University, Aalborg, Denmark. From 2006 to 2007, he was with the Division of Electronics and Information Engineering, Chonbuk National University, Jeonju, Korea. In 2007 he joined the School of Electrical and Computer Engineering, Ajou University, Suwon, Korea. He is an associated editor of the IEEE Transactions on Power Electronics, IEEE Transactions on Industrial Electronics and the Journal of Power Electronics. He has received two IEEE prize paper awards. His research interests include electric machine drives and renewable power generations. 